\title{
Public service motivation as a mediator of the relationship between job stress and presenteeism: a cross-sectional study from Chinese public hospitals
}

\author{
Jianwei Deng ${ }^{1,2}$, Yaxin Li ${ }^{1}$, Yangyang Sun ${ }^{1}$, Run Lei ${ }^{1}$ and Tianan Yang ${ }^{1,2,3^{*}}$ C
}

\begin{abstract}
Background: Job stress is a strong indicator of presenteeism, but few studies have examined its diverse effects and mediators on presenteeism. This study explored the relationships between job stress, public service motivation (PSM) and presenteeism and how job stress and PSM influence presenteeism in a large national sample of Chinese healthcare workers.

Methods: A cross-sectional survey including 1392 healthcare workers from 11 Class A tertiary hospitals in eastern, central and western China was used in the analysis. Descriptive statistical analysis, correlation analysis and structural equation modeling were used to test the research hypothesis.

Results: Hindrance stress was inversely associated with PSM $(\beta=-0.27 ; P<0.001)$ but significantly positively associated with presenteeism $(\beta=0.35 ; P<0.001)$. PSM was directly inversely associated with presenteeism $(\beta=-$ $0.35 ; \mathrm{P}<0.001)$. PSM partially mediated the relation of hindrance stress with presenteeism.

Conclusions: The findings suggest that efforts to prevent presenteeism among healthcare workers in China should emphasize PSM improvement and reduction of hindrance stress.
\end{abstract}

Keywords: Challenge stress, Hindrance stress, PSM, Presenteeism, Healthcare service, Big data

\section{Background}

Presenteeism refers to the "potential productivity loss in the workplace due to health and other events" [1]. Presenteeism has been a focus of organizational and human resource management research, because scholars are beginning to realize that presenteeism is a hidden but significant drain on productivity [2] and that it has a greater effect than actual absence on the overall productivity of an organization. Although presenteeism is clearly a substantial financial problem for organizations [3], few studies have examined its antecedents and mechanisms. Job stress is thought to be the main indicator of presenteeism, as it leads to

\footnotetext{
* Correspondence: yangtianan@gmail.com

'School of Management and Economics, Beijing Institute of Technology, No.

5 South Zhongguancun Street, Beijing 100081, People's Republic of China

${ }^{2}$ Sustainable Development Research Institute for Economy and Society of

Beijing, No. 5 South Zhongguancun Street, Beijing 100081, China
}

Full list of author information is available at the end of the article presenteeism by adversely affecting the physical condition of employees [4-6].

Job stress is usually assumed to include multiple dimensions. Cavanaugh et al. reported that challenge stress and hindrance stress underlay scores on items from several popular measures of stress. Challenge stress was viewed by managers as obstacles to be overcome in order to learn and achieve, including high workload, time pressure, job scope and high responsibility. Hindrance stress included stressful demands viewed by managers as unnecessary impediments to personal growth and goal attainment, such as organizational politics, red tape, role ambiguity and concerns about job security [7]. Different types of job stress are usually considered to have diverse effects on productivity-related outcomes [1]. However, existing studies usually analyzed job stress as an aggregate variable and few have assessed how different types of stress affect presenteeism. Thus, 
we explored how challenge stress and hindrance stress differentially affect presenteeism.

In addition to affecting the physical condition of employees, job stress may lead to presenteeism by affecting employees' psychological condition, including their public service motivation (PSM). Broadly speaking, PSM is "an individual's predisposition to respond to motives grounded primarily or uniquely in public institutions and organizations" [8]. A commitment to the public interest, service to others, engagement in prosocial behavior and self-sacrifice underlie the understanding of PSM [8-10]. On the one hand, some common stressors (e.g., red tape, leadership style and other organizational factors) are considered to be important antecedents of PSM [11-13]. Although people become insensitive to others (e.g., by decreased helping and recognition of individual differences and increased aggression) as job stress increases [14, 15], the effects of various types of job stress differ. In a meta-analysis, Lepine et al. tested the impact of different types of job stress and found that challenge stress was associated with high motivation, because people were likely to believe that there is a positive relationship between effort expended on coping with these demands and the likelihood of meeting the demands. Moreover, they were likely to believe that if these demands were met, valued outcomes would occur. However, hindrance stressors were associated with low motivation, because people were unlikely to believe in the presence of a relationship between effort expended on coping with these demands and the likelihood of meeting them [16]. Later, Deng et al. reported that challenge stress was significantly positively associated with PSM, while hindrance stress had adverse effects [17]. On the other hand, PSM might determine the way in which we conceptualize things, which shapes our desires and actions [18]. This would lead to a huge potential loss in productivity, or presenteeism, if PSM was not seriously considered in public-sector employees. Simone et al. examined Spanish civil servants and found that PSM was significantly positively associated with work engagement, which could partly prevent presenteeism [19]. Thus, PSM is important in the relationship between job stress and presenteeism $[1,20]$.

Person-organization fit theory might further explain the mediating effect of PSM on the relation between job stress and presenteeism. The study of PSM is closed related to the person-organization fit theory, which holds that individual psychology and behavior result from the interaction between persons and organizations. PSM assumes that civil servants are committed to serving the public [10]. Healthcare workers in China prefer to work in the public sector and usually exhibit strong work ability and job performance at the beginning of their employment, when PSM is high and organizations fit them well. However, organizational changes could cause friction between the worker and organization. When employees are in a work environment with high job demands and stress, the imbalance between the individual and organization could alter their PSM and even cause considerable productivity loss, or presenteeism [21, 22].

We targeted Chinese healthcare workers in public hospitals in this study because they provide most health services in China [23] and suffer from long working hours, a high-intensity work pattern and poor physician-patient relations [24-26]. These factors typically cause Chinese healthcare workers to have high job stress and presenteeism [27]. Additionally, public hospitals are an important part of the public sector in China. Employees in public sectors are usually considered to have high PSM [28, 29].

Overall, this study focuses on the relationship between job stress, PSM and presenteeism. It examines the mediating effect of PSM on the association between job stress and presenteeism and the effects of different types of job stress on PSM and presenteeism (Fig. 1). This study has potential theoretical and practical contributions. First, it investigated the mediating effects of PSM on the relationship between job stress and presenteeism, which contributes to research on mediators between job stress

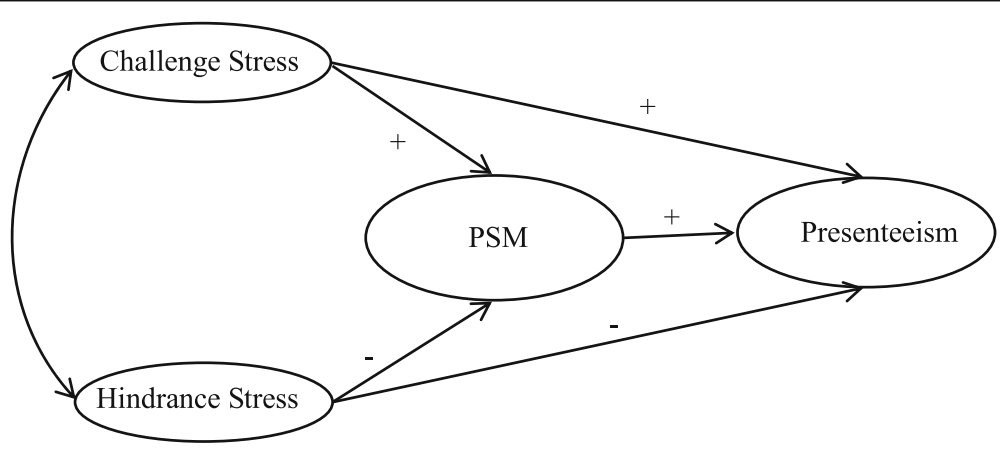

Fig. 1 Proposed model of how challenge stress, hindrance stress, and PSM affect presenteeism 
and presenteeism. Second, the present study yielded practical information on the differential effects of various types of job stress on PSM and presenteeism [17, 27]. Third, it provides empirical evidence regarding the effects of PSM on other psychological constructs and work-related outcomes [30, 31]. Finally, this study provides useful information on how managers of public hospitals seeking to reduce medical costs and improve healthcare quality might effectively motivate and improve the performance of healthcare workers.

\section{Methods}

\section{Sample}

This cross-sectional study was conducted in 11 randomselected representative Class A tertiary hospitals in eastern $(n=5)$, central $(n=3)$ and western $(n=3)$ China in 2016, in accordance with the ratios of the number of Class A tertiary hospitals in these three regions (5.2: 3.6: 2.6). Ethics approval was received from an independent research ethics committee in China. Because most healthcare services in China are provided by public hospitals and because Class A tertiary hospitals (more than 1000 employees and more than 500 beds) provide the highest level of healthcare services in the country, we included these hospitals in this study. Each study participant provided informed consent. Questionnaires were dispatched on the spot and collected after a pre-specified time to ensure comparability. After random sampling by geographical area and employee ID, we identified and ultimately analyzed data from 1392 participants (including doctors, nurses, pharmacists, medical technicians, and administrative personnel in hospitals and clinics; response rate $97.5 \%)$.

\section{Assessment tools}

\section{Job stress scale}

Job stress was measured with the Challenge and Hindrance-related Self-reported Stress (C-HSS) scale of 11 items, which has been widely used and has been proven to have good reliability and validity [7, 17]. Six items were used to measure challenge stress, and five items were used for hindrance stress. For example, the item, "The number of jobs (or tasks, projects) I undertake", asks respondents to rate their challenge stress and hindrance stress on a 5 -point Likert scale $(1=$ no stress; $5=$ great stress). Higher values reflect greater job stress. In our research, the C-HSS scale was shown to have high reliability $(\alpha=0.91-0.83)$.

\section{PSM scale}

PSM was measured with a reliable and validated scale developed by Vandenabeel [32] and validated in previous studies [17]. It includes 18 items in five dimensions: attraction for public policy making (two items), public interest (four items), compassion (five items), self-sacrifice (four items) and democratic governance (three items). The item, "I volunteer to contribute to my community selflessly", asks respondents to rate their importance to the public interest on a scale from 1 (strongly disagree) to 5 (strongly agree). To make the score more consistent and intuitive, we changed the score directionality of three reverse items by subtracting the original scores from 5. Therefore, higher values reflect greater PSM. In the present study, the scale has high reliability $(\alpha=0.836)$.

\section{Presenteeism scale}

Presenteeism was assessed with the Perceived Ability to Work Scale (PAWS), a robust and reliable instrument comprising four items measuring perceived productivity loss. The PAWS had acceptable psychometric properties in previous studies and in a national survey of the United States [33, 34]. The item, "When thinking about the mental demands of your job, how do you rate your current ability to meet those demands?" asks respondents to rate their perceived physical ability on a scale from 0 to $10(0=$ cannot currently work at all; $10=$ work ability is currently at its lifetime best). The scale has high reliability $(\alpha=0.89)$ and acceptable psychometric properties. To understand the score more intuitively, we changed score directionality by subtracting the original scores from 10. Therefore, higher scores indicate greater presenteeism.

\section{Data analysis}

This study used SPSS 20.0 and AMOS 20.0 for the statistical analyses, which included data imputation, descriptive analysis, correlation analysis and structural equation modeling (SEM). The SEM analysis was used to investigate the relationships between challenge stress, hindrance stress, PSM and presenteeism. SEM can identify effect relationships among variables, which are classified as direct or indirect $[35,36]$.

Imputation was conducted to address the missing values using Expectation-Maximization. Finally, we used the Sobel test to examine the significance of mediated effects $[37,38]$. We also used correlation analysis to determine the significance of the correlations between challenge stress, hindrance stress, PSM and presenteeism.

Before conducting SEM, we conducted confirmatory factor analysis to confirm that our model fitted the data well. In SEM, the four latent variables were challenge stress, hindrance stress, PSM and presenteeism. The criteria used to evaluate the model were a root mean square error of approximation less than 0.08 and normed fit and comparative fit indices greater than 0.90 , which indicate good model fit $[39,40]$. 


\section{Results}

\section{Description of respondents}

Table 1 shows the characteristics of the final sample after excluding participants without any response. Demographic information was missing for a few participants $(3.3$ to $5.9 \%$ ), and $21.3 \%$ of respondents were men. Only $3.7 \%$ of participants were older than 50 years; most (38.6\%) were 25 to 30 years of age. Nearly one third of participants $(29.4 \%)$ had a master's degree or higher graduate degree, and $41.5 \%$ had undergraduate degrees. Half of respondents had less than 5 years of work experience, $22.1 \%$ had 6 to 10 years of work experience, and $24.0 \%$ had more than 10 years of work experience. Most participants were nurses $(42.3 \%)$ or clinicians $(30.5 \%)$. In terms of job title, $53.1 \%$ had a junior title, $27.6 \%$ had a mid-level title, and $8.6 \%$ had a senior title. Pediatrics (18.7\%), internal medicine (16.5\%) and surgery (16.2\%) were the most common departmental affiliations; only $0.9 \%$ of participants were in the oncology department.

From Table 2 it can be seen that the mean for the challenge stress $(M=3.47, S D=0.87)$ was higher than that for hindrance stress $(M=2.85, \mathrm{SD}=1.03)$. Mean PSM score was $3.72(\mathrm{SD}=0.94)$. The average level for presenteeism was $2.59(\mathrm{SD}=1.68)$.

\section{Correlations among study variables}

Table 2 displays the correlations between challenge stress, hindrance stress, PSM and presenteeism. The correlation coefficients ( $r$ ) for items within the same construct (Table 2) were positively correlated. PSM was significantly negatively correlated with challenge stress $(\beta=-0.077, p<0.01)$ and hindrance stress $(\beta=-0.025$, $\mathrm{p}<0.01)$, and presenteeism was significantly positively correlated with challenge stress $(\beta=0.196, \mathrm{p}<0.01)$ and hindrance stress $(\beta=0.315, \mathrm{p}<0.01)$. However, PSM was significantly inversely correlated with presenteeism $(\beta=$ $-0.353, p<0.01)$. Of note, challenge stress was significantly positively correlated with hindrance stress $(\beta=$ $0.532, \mathrm{p}<0.01)$.

\section{SEM}

First, we used the Harman Single Factor score to identify common method bias (CMB). All items (measuring latent variables) were loaded into a common factor. When the total variance for a single factor is less than $50 \%$, the data are not likely to have been affected by CMB [41, 42]. We performed the Harman Single Factor test and found that the newly introduced single factor accounted for $24.38 \%$ of the variance, which is below the threshold for common method bias (.50). Therefore, we conclude that there was no common method bias in the data.

Then, analysis of the measurement model showed that our model fitted the data well because the values for the goodness-of-fit and comparative fit indices of each measurement model were all between 0.904 and 0.926 . The chi-square values (degrees of freedom and $p$-values) for the measurement model of challenge stress, hindrance stress, PSM and presenteeism were 375.678 (9, $p<0.001), 61.361$ (5, p<0.001), 353.728 (5, p<0.001) and $32.30(2, \mathrm{p}<0.001)$, respectively. In the final model (Fig. 2), PSM was directly inversely associated with presenteeism $(\beta=-0.35 ; P<0.001)$. Hindrance stress was negatively associated with PSM $(\beta=-0.27 ; \mathrm{P}<0.001)$ but significantly positively associated with presenteeism $(\beta=0.35 ; \mathrm{P}<0.001)$. However, the path from challenge stress to PSM $(\beta=0.06 ; P=0.16)$ and presenteeism $(\beta=$ $0.01 ; P=0.76)$ was not significant. There was a direct positive association between challenge stress and hindrance stress $(\beta=0.62 ; \mathrm{P}<0.001)$. Challenge stress and hindrance stress explained $6 \%$ of the variability in PSM. Challenge stress, hindrance stress and PSM explained $24 \%$ of variability in presenteeism. Criteria for fitness, such as root mean square error of approximation, goodness-of-fit index, comparative fit index and normed fit index, indicated that the revised model was more appropriate (Fig. 2).

Finally, the indirect effect was only significant between hindrance stress and presenteeism (Sobel $\mathrm{z}=5.28 ; p<$ 0.001 ), while the indirect effect between challenge stress and presenteeism (Sobel $\mathrm{z}=-1.54 ; p=0.16$ ) was not. The relationship between hindrance stress and presenteeism was partly significantly mediated by PSM.

\section{Discussion}

Job stress is a strong indicator of presenteeism, but previous studies have mostly considered job stress as an aggregate variable and focused on the negative effects of job stress on presenteeism. We also know that job stress not only directly affects presenteeism, but also leads to presenteeism by adversely affecting individual health [4, 27]. Whether job stress leads to presenteeism by affecting the psychological condition of employees is unclear. Therefore, we used national survey data from 1392 Chinese healthcare workers to explore the positive and negative effects of job stress on presenteeism and the mediating effect of PSM on the relationship between job stress and presenteeism, which yielded the following important findings.

First, hindrance stress had a negative effect on PSM and a positive effect on presenteeism, which partially confirms the findings of some previous studies. Most of those studies concluded that hindrance stress would adversely affect individual psychology and behavior, resulting in exhaustion, burnout, boredom, loss of enthusiasm and composure and erosion of motivation to learn and work [43-45]. According to the person-organization fit theory, the degree and type of job stress significantly affect the fit between a person and organization, thus 
Table 1 Demographic characteristics of participating healthcare workers ( $N=1392)$

\begin{tabular}{lll}
\hline Characteristics & Sample $(n=1392)$ & $\%$ \\
\hline $\begin{array}{l}\text { Gender } \\
\text { Male }\end{array}$ & 297 & $21.3 \%$
\end{tabular}

Female 1037

Age (years)

$\sim 25$

25 30

$31 \sim 35$

538

302

36 40

$41 \sim 50$

51 55

56 60

60

Post

Clinician

Nurse

Management

Medical technician

Pharmacist

Education

Undergraduate

Junior college

Undergraduate

Master

Doctor

Title

$\begin{array}{ll}\text { Trainee } & 67 \\ \text { Junior } & 739\end{array}$

Mid-level

Senior

Seniority (years)

$\sim 3$

$3 \sim 5$

$6 \sim 10$

11 20

20

Department

Physician

Surgeon

Obstetrics and Gynecology

Pediatrics

Chinese Medicine

Oncology

Other clinical Departments
$74.5 \%$

$13.6 \%$

$38.6 \%$

$21.7 \%$

$9.2 \%$

$9.9 \%$

$2.9 \%$

$0.6 \%$

$0.2 \%$

$30.5 \%$

$42.3 \%$

$8.5 \%$

$11.4 \%$

$1.8 \%$

$3.8 \%$

$41.5 \%$

$21.5 \%$

$7.9 \%$

$4.8 \%$

$53.1 \%$

$27.6 \%$

$8.6 \%$

$24.5 \%$

$25.5 \%$

$22.1 \%$

$13.9 \%$

$10.1 \%$

$16.5 \%$

$16.2 \%$

$9.5 \%$

$18.7 \%$

$7.3 \%$

$0.9 \%$

$6.0 \%$
$21.2 \%$
Table 1 Demographic characteristics of participating healthcare workers $(N=1392)$ (Continued)

\begin{tabular}{lll}
\hline Characteristics & Sample $(n=1392)$ & $\%$ \\
\hline Medical technology & 181 & $13.0 \%$ \\
Administration and Logistics & 90 & $6.5 \%$ \\
\hline
\end{tabular}

affecting individual psychology and behavior [10]. Hindrance stress forces employees to focus on work context and interpersonal relationships rather than on work duties and service, and to pursue personal interests rather than public interests. Therefore, hindrance stress could cause friction between a person and organization, thereby decreasing PSM and increasing presenteeism.

Second, PSM was significantly negatively correlated with presenteeism. Although very few studies have investigated the effect of PSM on presenteeism, PSM has been linked to several positive work outcomes, such as job involvement, organizational commitment and organizational citizenship behavior [29, 46, 47]. These positive work outcomes indicate greater work ability and better job performance. The present study defined presenteeism from the perspective of productivity loss; thus, people with high PSM might have lower presenteeism. In addition, we can view this result from the perspective of PSM theory, which holds that public-sector employees with high PSM are more likely to have high job performance and provide more work input [48]. In China, healthcare workers in public hospitals are public servants, a group usually considered to have higher PSM and to be more altruistic. Therefore, they are more focused on their work and on overcoming problems related to health, work, family and interpersonal relationships, which would increase productivity and reduce presenteeism.

Third, as expected, PSM mediated the relationship between hindrance stress and presenteeism. Most previous studies regarded health as a main mediating variable between job stress and presenteeism. For example, job stress caused headache, neck pain and strain, thereby increasing presenteeism [49]. However, job stress may also reduce enthusiasm and motivation for work, which would increase presenteeism. The present study provides empirical evidence that PSM partially mediates the

Table 2 Pearson Correlations between Presenteeism, Stress, and PSM

\begin{tabular}{lllllll}
\hline & Mean & SD & 1 & 2 & 3 & 4 \\
\hline Challenge stress & 3.47 & 0.87 & 1 & & & \\
Hindrance stress & 2.85 & 1.03 & $0.532^{* *}$ & 1 & & \\
PSM & 3.72 & 0.94 & $-0.077^{* *}$ & $-0.225^{* *}$ & 1 & \\
Presenteeism & 2.59 & 1.68 & $0.196^{* *}$ & $0.315^{* *}$ & $-0.353^{* *}$ & 1 \\
\hline Notes. ${ }^{*} p<0.01$ & & & & & &
\end{tabular}




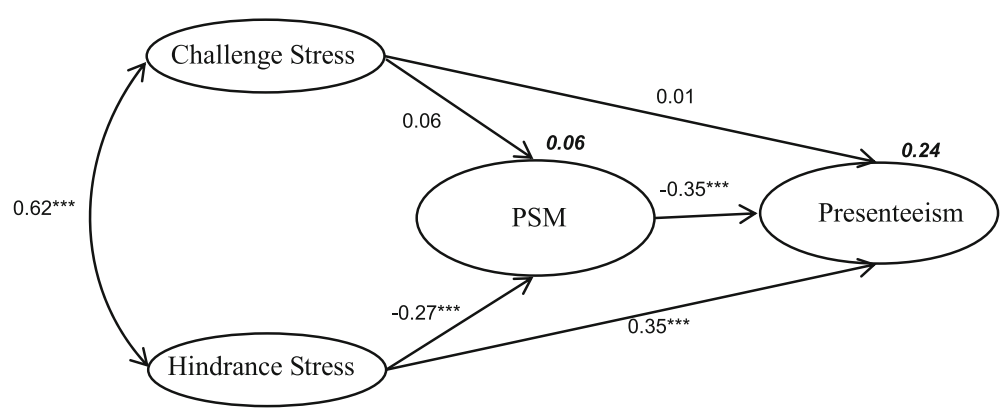

Fig. 2 Final model illustrating how challenge stress and hindrance stress influence PSM and presenteeism (Notes. ${ }^{* *} p<0.001$ ). (numbers not in bold are standardized regression coefficients and numbers in bold explain variability; chi square, 1381.091; degrees of freedom, 164, $p<0.001$; root mean square error of approximation, 0.073; normed fit index, 0.917; comparative fit index, 0.926; *** $p<0.001$ )

effects of hindrance stress and presenteeism. This result shows that in Chinese public hospitals hindrance stress affects healthcare workers' presenteeism through PSM and other factors. A future study should target PSM as a predictor of presenteeism.

Overall, this study focuses on the relationship between job stress, PSM and presenteeism. Our findings indicate that hindrance stress has a negative effect on PSM and a positive effect on presenteeism. To improve the quality of health service and decrease counterproductive behaviors (presenteeism) among Chinese healthcare workers, the first priority is to reduce job stress, especially hindrance stress. Managers of public hospitals, for example, should create an environment that supports workers by arranging appropriate workloads or reducing red tape and by promoting job security [50]. In addition, because PSM indirectly mediates the association between job stress and presenteeism, its effect on coping with job stress and presenteeism should be considered as part of policy-making and management. Managers of public hospitals should optimize staff recruitment and selection to attract individuals with high PSM [51].

\section{Limitations}

Our study has several limitations. First, all data were selfreported. Recall, personal perception and perceived stress when completing the questionnaire might have affected the accuracy and objectivity of the assessment and could have introduced bias. Future studies should consider both subjective and objective data on job stress, PSM and presenteeism. Second, our conclusions are based on a crosssectional database, which limits inferences regarding causality. A third limitation is that the research focused on healthcare workers in Class A tertiary hospitals and excluded those in primary and secondary hospitals, which limits the generalizability and robustness of our conclusions. Therefore, in the future, healthcare workers from primary and secondary hospitals should be included in the research, to verify our hypothesis and models. Finally, the psychometric properties of the Chinese versions of the scales used in this study have not been assessed in a large sample. Nevertheless, we feel that these limitations do not invalidate the present conclusions.

\section{Conclusion}

PSM has a mediating role in the association between job stress and presenteeism among hospital employees. Both dimensions of reported job stress (challenge stress and hindrance stress) have adverse effects on PSM. Hindrance stress is positively associated with presenteeism, but challenge stress does not significantly directly affect presenteeism. To improve job performance and service quality among healthcare workers, job stress should be reduced and PSM increased. Managers of public hospitals should create an environment for workers that limits worker stress and reduces presenteeism.

\section{Abbreviations}

C-HSS: Challenge and Hindrance-related Self-reported Stress;

PAWS: Perceived Ability to Work Scale; PSM: Public Service Motivation;

SEM: Structural Equation Modelling

\section{Acknowledgements}

The authors thank research assistants in our representative hospitals for their support for the data collection in our study.

\section{Authors' contributions}

JD and TY conceived of and designed the study. JD, YL, YS, RL and TY contributed to the data collection, data management, statistical analysis, interpretation of the results, and revision of the manuscript. JD wrote the paper. All authors have read and agreed on the final version.

\section{Funding}

This study was supported by National Science Funding of China (grant no. 71804009, 71974011, 91746116, 71972012, 71603018), Beijing Social Science Foundation (grant no. 17GLC043, 17JDGLB008), MOE Project of Humanities and Social Sciences (grant no. 16YJC630017), Special Plan for Basic Research of Beijing Institute of Technology (grant no. 20192142002), Special Fund for Joint Development Program of Beijing Municipal Commission of Education. The funders had no role in the design of the study and collection, analysis, and interpretation of data and in writing the manuscript.

\section{Availability of data and materials}

The datasets used and/or analyzed during the current study are available from the corresponding author on reasonable request. 


\section{Ethics approval and consent to participate}

Written informed consent was obtained from all study participants. All procedures related to the study of human participants were approved by the Institutional Research Board of the First Affiliated Hospital of Xiamen University (No. KYX2016007).

\section{Consent for publication}

Not applicable.

\section{Competing interests}

The authors declare that they have no competing interests.

\section{Author details}

${ }^{1}$ School of Management and Economics, Beijing Institute of Technology, No. 5 South Zhongguancun Street, Beijing 100081, People's Republic of China. ${ }^{2}$ Sustainable Development Research Institute for Economy and Society of Beijing, No. 5 South Zhongguancun Street, Beijing 100081, China. ${ }^{3}$ Chair of Sport and Health Management, School of Management, Technical University of Munich, Uptown Munich Campus D, Georg-Brauchle-Ring 60/62, 80992 Munich, Germany.

Received: 21 February 2019 Accepted: 28 August 2019

Published online: 03 September 2019

\section{References}

1. Yang $T$, Lei $R$, Jin X, et al. Supervisor support, Coworker Support and Presenteeism among Healthcare Workers in China: The Mediating Role of Distributive Justice. Int J Environ Res Public Health. 2019;16:817.

2. Hemp P. Presenteeism: at work--but out of it. Harv Bus Rev. 2004;82:49-58.

3. Goetzel RZ, Long SR, Ozminkowski RJ, et al. Health, absence, disability, and presenteeism cost estimates of certain physical and mental health conditions affecting U.S. employers. J Occup Environ Med. 2004;46:398-412.

4. Elstad JI, Vabø M. Job stress, sickness absence and sickness presenteeism in nordic elderly care. Scand J Public Health. 2008;36:467-74.

5. Yang T, Zhu M, Xie X. The determinants of presenteeism: a comprehensive investigation of stress-related factors at work, health, and individual factors among the aging workforce. J Occup Health. 2016;58:25-35.

6. Dua JK. Job stressors and their effects on physical health, emotional health and job satisfaction in a university. J Educ Admin. 1994;32:59-78.

7. Cavanaugh MA, Boswell WR, Roehling MV, et al. An empirical examination of self-reported work stress among U.S. managers. J Appl Psychol. 2000;85 65-74.

8. Perry JL. Measuring public service motivation: an assessment of construct reliability and validity. J Publ Adm Res Theor. 1996;6:5.

9. Brewer GA, Selden SC. Whistle blowers in the federal civil service: new evidence of the public service ethic. J Publ Adm Res Theor. 1998;8:413-39.

10. Houston DJ. "walking the walk" of public service motivation: public employees and charitable gifts of time, blood, and money. J Publ Adm Res Theor. 2006;16:67-86.

11. Scott PG, Pandey SK. Red tape and public service motivation findings from a national survey of managers in state health and human services agencies. Rev Public Pers Adm. 2005;25:155-80.

12. Quratulain S, Khan AK. Red tape, resigned satisfaction, public service motivation, and negative employee attitudes and behaviors: testing a model of moderated mediation. Rev Public Pers Adm. 2015;35:307-32.

13. Vandenabeele WV. Who wants to deliver public service? Do institutional antecedents of public service motivation provide an answer? Rev Publ Person Admin. 2011;31:87-107.

14. Cohen S. After effects of stress on human performance and social behavior: a review of research and theory. Psychol Bull. 1980;88:82-108.

15. Coursey D, Pandey SK. PSM and support for citizen participation: a test of Perry and Vandenabeele's reformulation of PSM theory. Public Adm Rev. 2012;72:572-82

16. Lepine A, Podsakoff $P$, Lepine M. A meta-analytic test of the challengehindrance stressor framework: an explanation for inconsistent relationships among stressors and performance. Acade Ma J. 2005:48:764-75.

17. Deng J, Guo Y, Ma T, et al. How job stress influences job performance among Chinese healthcare workers: a cross-sectional study. Envir Health Pre Med. 2019:24:8-14.

18. Goleman D. Emotional intelligence. Graw-Hill: New York. Mc; 2000.
19. Simone D, Cicotto G, Pinna R, et al. Engaging public servants: public service motivation, work engagement and work-related stress. Manage Decis. 2016; 54:1569-94.

20. Johns G. Presenteeism in the workplace: a review and research agenda. J Organ Behav. 2010;31:519-42.

21. Dabate CP. Working hard or hardly working: a study of individuals engaging in personal business on the job. Hum Relat. 2005;58:1009-32.

22. Wan HC, Downey LA, Stough C. Understanding non-work presenteeism: relationships between emotional intelligence, boredom, procrastination and job stress. Pers Individ Dif. 2014;65:86-90.

23. Eggleston K, Lu MS, Li CD, et al. Comparing public and private hospitals in China: evidence from Guangdong. BMC Health Serv Res. 2010;10:76.

24. Lancet T. Ending violence against doctors in China. Lancet. 2012;379:1764.

25. Hesketh T, Wu D, Mao L, et al. Violence against doctors in China. Lancet. 2012:384:e5730.

26. Listed N. Violence against doctors: why China? Why now? What next? Lancet. 2014;383:1013.

27. Yang $T$, Ma M, Zhu M, et al. Challenge or hindrance: does job stress affect presenteeism among Chinese healthcare workers. J Occup Health. 2018; 60:163-71.

28. Bright $\mathrm{L}$. Does person-organization fit mediate the relationship between public service motivation and the job performance of public employees? Rev Public Pers Adm. 2007;27:361-79.

29. Bright $L$. Does public service motivation really make a difference on the job satisfaction and turnover intentions of public employees? Am Rev Public Adm. 2008;38:149-66.

30. Palma R, Sepe E. Structural equation modelling: a silver bullet for evaluating PSM. Qual Quant. 2017;51:729-44.

31. Perry L, Hondeghem A, Wise R. Revisiting the motivational bases of public service: twenty years of research and an agenda for the future. Public Adm Rev. 2010;70:681-90.

32. Vandenabeel W. Development of a public service motivation measurement scale: corroborating and extending Perry's measurement instrument. Int Publ Manag J. 2008;11:143-68.

33. Vänni K, Virtanen P, Luukkaala T, et al. Relationship between perceived work ability and productivity loss. Int J Occup Saf Ergon. 2012;18:299-309.

34. Ilmarinen J, Rantanen J. Promotion of work ability during ageing. Am J Ind Med. 1999:36:21-3.

35. Bollen KA, Long JS. Testing structural equation models. Bull Soc Meth. 1993; 23:66-7.

36. Hu LT, Bentler PM. Fit indices in covariance structure modeling: sensitivity to models. Sociol Methodol. 1998;13:290-312.

37. Mackinnon DP, Lockwood CM, Hoffman JM, et al. A comparison of methods to test mediation and other intervening variable effects. Psychol Methods. 2002;7:83-97.

38. Sobel ME. Asymptotic confidence intervals for indirect effects in structural equation models. Soc Met. 1982;13:290-312.

39. Ullman JB. Structural equation modeling. In: Tabachnick BG, Fidell LS, editors. Using multivariate statistics. Boston, MA: Pearson Education; 2001.

40. Anna C. Estimation methods for the structural equation models: maximum likelihood, partial least squares and generalized maximum entropy. J app quant met. 2012:7:3-17.

41. Podsakoff PM, MacKenzie SB, Lee JY, et al. Common method biases in behavioral research: a critical review of the literature and recommended remedies. J App Psychol. 2003;88:879-903.

42. Podsakoff PM, MacKenzie SB, Podsakoff NP. Sources of method bias in social science research and recommendations on how to control it. Annu Rev Psychol. 2012:63:539-69.

43. Lepine JA, Lepine MA, Jackson CL. Challenge and hindrance stress: relationships with exhaustion, motivation to learn, and learning performance. J Appl Psychol. 2004;89:883.

44. Yao AY, Jamal M, Demerouti E. Relationship of challenge and hindrance stressors with burnout and its three dimensions. Journal of Personnel Psychology. 2014;14:203-12.

45. Husen S. Challenge stress, hindrance stress and work related outcomes: a cross cultural study. John Molson School of Business: Concordia University. Montreal, Quebec, Canada, March; 2009.

46. Kim S. Public service motivation and organizational citizenship behavior in Korea. Int J Manpow. 2006:27:722-40.

47. Camilleri E. Towards developing an organizational commitment - public service motivation model for Maltese public service employees. Public Policy Adm. 2006;21:63-83. 
48. Leisink PLM, Steijn AJ. Public service motivation and job performance of public sector employees in the Netherlands. Int Rev Adm Sci. 2009;75:35-52.

49. Aronsson G, Gustafsson K, Dallner M. Sick but yet at work. An empirical study of sickness presenteeism. J Epidemiol Commun H. 2000;54:502-9.

50. Wong K. Work support, psychological well-being and safety performance among nurses in Hong Kong. Psychol Health Med. 2018;23:1-6.

51. Arson FB, Allan J, Johnston D, et al. Stress amongst nurses working in a healthcare telephone advice service: relationship with job satisfaction intention to leave, sickness absence, and performance. J Adv Nurs. 2012;68: 1624-35.

\section{Publisher's Note}

Springer Nature remains neutral with regard to jurisdictional claims in published maps and institutional affiliations.

Ready to submit your research? Choose BMC and benefit from:

- fast, convenient online submission

- thorough peer review by experienced researchers in your field

- rapid publication on acceptance

- support for research data, including large and complex data types

- gold Open Access which fosters wider collaboration and increased citations

- maximum visibility for your research: over $100 \mathrm{M}$ website views per year

At $\mathrm{BMC}$, research is always in progress.

Learn more biomedcentral.com/submissions 